\title{
Recuperação da automanutençáo de paciente com traumatismo cranioencefálico: um estudo de caso
}

\author{
Vanessa Maciel Oliveira ${ }^{a}$, Miriam Cândida Silva e Dias ${ }^{b}$ \\ aTerapeuta ocupacional, especialização em Gestão em Promoção e Prevenção em Saúde, \\ Departamento de Pós-graduação Saúde, Faculdade Pitágoras - PSES, Belo Horizonte, MG, Brasil \\ ${ }^{\text {b}}$ Terapeuta ocupacional, mestrado em Administração, Departamento de Pós-graduação da Faculdade \\ Novos Horizontes - FNH, Belo Horizonte, MG, Brasil
}

\begin{abstract}
Resumo: Este trabalho situa-se na área de neurologia em adultos e foi produzido a partir produzido a partir da prática vivenciada em atendimentos domiciliares, com uma paciente que sofreu traumatismo cranioencefálico (TCE). Nesse cenário, apresentam-se aqui dados referentes à pesquisa de caráter qualitativo e descritivo. O objetivo da pesquisa foi, sob forma de estudo de caso, ilustrar as referências técnicas e científicas requeridas na formulação da prática do terapeuta ocupacional. O eixo condutor do tratamento executado foi recuperar habilidades necessárias para estar apto a realizar a automanutenção. A paciente foi acompanhada pelo serviço de terapia ocupacional pelo período de um ano. Os atendimentos ocorriam em seu domicílio, duas vezes por semana. Foram utilizadas duas abordagens na reabilitação da paciente em estudo: neurofacilitação/neuroevolutiva e reaprendizagem do controle motor. Estas visam recuperar ou desenvolver habilidades que serão utilizadas pelo sujeito em suas atividades e tarefas. O processo de reabilitação foi conduzido sob a perspectiva da deficiência como parte de um estado de saúde e esteve sob a óptica holística. Há uma reflexão sobre o modelo e as abordagens adotadas; além de uma articulação entre o significado da recuperação da autonomia pessoal e o contexto social, e como esses aspectos se inter-relacionam no desempenho ocupacional, na saúde e na adaptação à doença ou incapacidade.
\end{abstract}

Palavras-chave: Terapia Ocupacional, Autonomia Pessoal, Traumatismos Craniocerebrais, Reabilitação.

\section{Self-maintenance recovery of a patient with traumatic brain injury: a case study}

\begin{abstract}
Occupational Therapy comprises a broad field of action; as a result, specific assistance areas have been created where professionals generally specialize according to their interests. This study on the area of adult neurology was carried out based on the practice experienced in homecare with a patient who suffered a traumatic brain injury (TBI). In this scenario, we present data on qualitative and descriptive research. This is a case study that illustrates the scientific and technical references required in the formulation of Occupational Therapy practice. The treatment was carried out to recover the necessary skills to enable self-maintenance performance. The patient was followed by occupational therapy service for one year. The sessions took place at the patient's home twice a week. We used two approaches in the rehabilitation of the patient studied: proprioceptive neuromuscular facilitation and motor relearning. This assistance aimed to regain or develop the skills used by the subject in his daily activities and tasks. The rehabilitation process was conducted from the perspective of disability as part of a health condition under the holistic standpoint. We reflect on the model and approaches taken, as well as on the link between the meaning of recovery of personal autonomy and social context, and on how these aspects are interrelated in occupational performance, health and adaptation to illness or disability.
\end{abstract}

Keywords: Occupational Therapy, Personal Autonomy, Craniocerebral Trauma, Rehabilitation.

Autor para correspondência: Vanessa Maciel Oliveira, Faculdade Ciências Médicas de Minas Gerais, Rua São Paulo, 1071, bloco B, sala 716, Centro, CEP 30170-907, Belo Horizonte, MG, Brasil, e-mail: vanessato2000@yahoo.com.br

Recebido em 17/2/2011; $1^{\text {a }}$ revisão: 27/3/2012; 2a revisão 24/4/2012; Aceito em 18/9/2012. 


\section{Introdução}

A Terapia Ocupacional tem um amplo campo de atuaçáo e em consequência disso foram criadas áreas específicas de trabalho, onde os profissionais, geralmente, se especializam de acordo com seus interesses. Foi escolhida como área para esta pesquisa a neurologia adulto, pois nela foi vislumbrada a possibilidade de atuar com sujeitos que tiveram uma capacidade funcional ótima e que por motivos diversos a perderam, sofrendo assim grandes transformaçôes. Este trabalho foi escrito a partir de uma vivência em atendimentos domiciliares com uma paciente que sofreu trauma cranioencefálico (TCE) e em consequência disso apresentou alteraçóes motoras, cognitivas e comportamentais. Muitos casos poderiam ter sido escolhidos para ilustrar o que é preconizado teoricamente, porém a escolha por este foi feita pela riqueza de dados inferidos no histórico ocupacional da paciente. Fatores, estes, que interferem no perfil desse sujeito e isso apareceu no seu envolvimento com o tratamento.

O estudo de caso caracteriza-se pela preservação da unidade do sujeito, sendo este analisado holisticamente. A análise dos dados disponíveis é, no estudo de caso, um processo complexo, náo linear, que implica em um trabalho de reflexão e interpretação, e que à medida que se realiza amplia-se o quadro de referências e informaçôes e vão se tecendo perguntas e respostas. (ALVES-MAZZOTTI, 1998, p. 130).

Para a formulação do tema desta pesquisa, algumas definições de terapia ocupacional foram consultadas. As definiçốes que vão ao encontro dos paradigmas que fundamentaram este trabalho estão descritas a seguir.

A Associação Brasileira de Terapia Ocupacional (ASSOCIAÇÃO..., 2012) caracteriza-a

[...] como uma profissão na qual o profissional tem competência para o diagnóstico do desempenho ocupacional nas áreas das atividades de vida diária, atividades instrumentais de vida diária, trabalho e produtivas, lazer ou diversão e nos componentes de desempenho sensório-motor, integração cognitiva e componentes cognitivos, habilidades psicossociais e componentes psicológicos. $\mathrm{O}$ foco do tratamento é auxiliar o indivíduo a desenvolver ou restaurar habilidades e melhorar sua adaptação para desempenhar as atividades que ele deseja e precisa, considerando seus potenciais, limitaçôes e sua história pessoal.

Em concordância com essa caracterização e acrescentando o termo práxis em sua definição, cito Machado (1991), que caracteriza a Terapia
Ocupacional como uma profissão que tem como objeto de estudo a práxis, ou seja, o homem em atividade e sua açáo refletida, portanto, atividade humana que visa o progresso do indivíduo e gera uma mudança na vida dele, conciliando ação e reflexão. Homem visto como organismo complexo e itinerante, que se coloca no mundo pelas relaçóes com sua família, trabalho, lazer e consigo mesmo. O indivíduo práxico é o ser evolutivo, criativo, expressivo, produtivo, lúdico e, portanto, transformador. $\mathrm{O}$ indivíduo práxico nesse sentido é então o referencial de saúde. Ou seja, o referencial de saúde é a saúde práxica (MACHADO, 1991).

Diante desses paradigmas, cabe ao terapeuta ocupacional mediar o sujeito durante suas atividades e oferecer-lhe ferramentas para alcançar seu aspecto práxico. No caso relatado foram oferecidas e aplicadas técnicas e abordagens que favorecem aquisição e aprimoramento de habilidades.

Duas abordagens usadas na reabilitação de pacientes com déficits neurológicos, neurofacilitação/ neuroevolutiva e reaprendizagem do controle motor, foram estudas e utilizadas no tratamento da paciente referida no estudo de caso. Estas visam recuperar ou desenvolver habilidades que serão utilizadas pelo sujeito em suas atividades e tarefas.

A abordagem neuroevolutiva descrita por Davies (1996a) emprega técnicas, tais como inputs sensoriais controlados, para afetar a resposta motora, ou seja, técnicas de inibição e facilitação. As técnicas de inibição são usadas para tratar problemas de tônus muscular e coordenação motora anormais. Após a normalização do tônus, utilizam-se técnicas de facilitação para ativar respostas posturais normais e o controle de tronco, treinar o suporte de peso e os movimentos sem suporte de peso no braço e na perna. Nessa abordagem os objetivos principais são: recuperar o comportamento motor, ou seja, dar ao paciente a sensação do movimento normal em seu lado hemiplégico; prover um sistema para reaprender movimentos normais de tronco, braço e perna; estimular diretamente os músculos a se contrair de maneira isométrica, excêntrica ou isotônica e ensinar maneiras de incorporar o lado afetado a tarefas ocupacionais. É direcionado à aquisição dos componentes do desempenho sensório-motor, que constituem pré-requisito para a função (DAVIES, 1996c).

A abordagem do Programa de Reaprendizagem Motora, criado e divulgado por Carr e Shepherd (2003), baseada em três fatores, que são reconhecidos como essenciais para aprendizagem da habilidade motora, e, portanto, essenciais para a reaprendizagem do controle motor. Os fatores são: eliminação da 
atividade muscular desnecessária; feedback e prática. O feedback se caracteriza por expressóes curtas e claras de palavras ou demonstração, dos movimentos a serem feitos ou $\mathrm{j}$ concluídos. A prática deve ser avaliada a cada sessáo e a partir da aumentar o nível de desempenho do paciente. Náo objetivo do tratamento trabalhar a força muscular e sim o controle muscular, ou seja, não necessário ativar o maior número de unidades motoras e sim controlar a atividade motora do número correto de unidades para a função específica. O movimento surge da interação entre processos múltiplos, incluindo processos perceptivos, cognitivos e motores de cada indivíduo e interaçóes entre o indivíduo, a tarefa e o ambiente. Essa abordagem mais indicada no desenvolvimento de habilidades, desempenho de tarefas e atividades (CARR; SHEPHERD, 2003).

O objetivo do Programa de Reabilitação Motora a prática de atividades específicas no treinamento do controle cognitivo sobre os músculos e sobre os componentes de movimento destas atividades, junto com a eliminação consciente de toda atividade muscular desnecessária. A reabilitaçáo por isso envolve a reaprendizagem de atividades reais do cotidiano e que tenha significado para o paciente, não se resumindo prática de exercícios (CARR; SHEPHERD, 1988, p. 45).

\section{Desenvolvimento}

\subsection{Descrição do caso}

I, paciente do sexo feminino, tem cerca de 70 anos. Mora em uma metrópole, com mais duas irmãs. Os dados do histórico ocupacional e do acidente foram transmitidos pela família, no nosso primeiro encontro.

Foi encaminhada para o serviço de terapia ocupacional pelo psiquiatra, um ano e três meses após ter sofrido o traumatismo cranioencefálico (TCE). A família traz como queixa principal as dificuldades de I em realizar suas atividades de rotina (alimentação, higiene, vestuário) sem auxílio. Isso estava comprometendo as relaçôes familiares, a paciente estava sentindo-se cada vez mais triste e desmotivada a realizar as atividades vitais e o convívio estava sendo bastante penoso para todos.

No histórico ocupacional de I consta que ela teve convivência com a temática política desde criança, por influência dos avós. $\mathrm{Na}$ adolescência, iniciou curso de graduação em história. Nessa época o país vivia a crise do golpe de 1964 e I engajou-se na militância política, na luta contra a ditadura militar. Com o recrudescimento da repressão, precisou abandonar a faculdade, a família, o lar. Alguns anos depois foi presa e levada a um centro de tortura e repressão, do qual foi a única sobrevivente. Apreendida e julgada pela justiça militar, foi condenada à prisão perpétua. I ficou presa por oito anos. À medida que a situaçáo do país avançava, suas penas foram revistas e, com a lei da anistia, reconquistou a liberdade. Nos anos seguintes, terminou sua graduação.

No ano de 2001 trabalhava como funcionária pública na área de administração. Encontrava-se em tratamento psiquiátrico por causa de um episódio grave depressivo com sintomas psicóticos. Solteira e sem filhos, morava sozinha, mantinha restrito convívio social e familiar. Em setembro deste ano foi encontrada em casa, pela faxineira, com graves ferimentos na cabeça (traumatismo craniano na região parieto-temporal). A causa do acidente é desconhecida.

Em decorrência do incidente passou por um período de seis meses hospitalizada. Durante esse período o prognóstico dos médicos era que se caso I sobrevivesse ao traumatismo cranioencefálico, o que era uma possibilidade remota, teria apenas uma vida vegetativa. Hoje encontra-se em tratamento com neurologista, psiquiatra, faz exercícios físicos sob supervisão de um personal trainer e os atendimentos de Terapia Ocupacional ocorrem duas vezes por semana em seu domicílio.

De acordo com o neurologista, o diagnóstico de I é hemiparesia espástica leve à direita, com afasia mista de característica fluente, apresentando alteraçóes cognitivas e comportamentais. O psiquiatra acrescenta o diagnóstico, segundo o CID 10, F29 (psicose não orgânica não especificada). Ambos relatam sobre alteraçôes de humor, memória, orientação no tempo e espaço, crítica, capacidade de resolução de problemas, expressão verbal. Essas alteraçôes também foram confirmadas na avaliação de Terapia Ocupacional. Nessa avaliação foram pesquisados dados sobre o histórico ocupacional e sobre as atuais habilidades funcionais. No aspecto funcional foi usada como método de avaliação a medida de independência funcional (MIF). De acordo com a pontuação obtida, pude constatar que ela precisa de uma assistência mínima, ou seja, supervisão, comando verbal e/ou demonstração para a realização da maioria das tarefas e pouca assistência física. Comumente náo realizava atividades de automanutenção sozinha, contava com o auxílio da cuidadora e seus familiares. Estes não tinham recursos/informaçóes para orientá-la durante o fazer e por isso se dispunham a fazer por ela. Apresentava marcha semi-independente, com equilíbrio acometido e independência nas transferências. Escutava e observava o que era dito 
e mostrado, mas com dificuldade de compreensão. I mostrou-se disposta a cooperar com o tratamento.

\subsection{Descrição dos atendimentos}

Na primeira visita à casa de I, fui recebida por uma de suas irmãs. I vem ao meu encontro caminhando com pouca dificuldade, porém usava os móveis para apoiar e favorecer o equilíbrio. Sentou-se com a ajuda da cuidadora e tomou um café. Enquanto a irmã de I respondia à anamnese, esta não pronunciou muitas palavras, somente "é sim...", "eu não sei nada". Tentamos introduzi-la na conversa, mas não obtivemos sucesso. A entrevista foi conduzida com cautela, principalmente por ser o nosso primeiro contato.

Para conhecer as famílias as condutas não devem ser invasivas, devem ser sensíveis, sem julgamento e respeitando os parâmetros da privacidade e exposição que os indivíduos indicam (domicílio geográfico, nível socialcultural e econômico, religiáo etc.). (AMARO, 2003, p. 64).

Também foi possível constatar características comuns em pacientes que sofrem lesão na região parieto-temporal, tais como:

[...] dificuldade na aprendizagem de habilidades que utilizam informaçôes referentes à posição do corpo no espaço e informações visuais, negligência completa do lado contralateral - incluindo o corpo -, alteraçóes na lateralidade, dificuldade para escrever (mesmo com a função motora preservada), dificuldade de cruzar a linha média do corpo, incapacidade de executar tarefas com sequências complexas. (SHUMWAY-COOK, 2003, p. 63).

I apresentava-se com labilidade emocional, insegurança nos próprios sentidos, baixo limiar de frustração. A cada dificuldade encontrada durante as atividades diárias abandonava o fazer. Esse comportamento também apareceu durante os primeiros atendimentos de Terapia Ocupacional. A cada açáo concluída era dado um feedback, com o objetivo de mostrar o que realmente estava acontecendo e a forma como estava atuando.

$\mathrm{O}$ treinamento para aprimorar a habilidade requer a compreensão da relação entre o estímulo ambiental e o controle dos movimentos intencionais direcionados ao objetivo, bem como a compreensão dos processos ativos envolvidos na detecção e atenção dada a pistas ambientais relevantes. A ligação entre cognição e ação não pode ser ignorada, e é improvável que a ação melhore sem o treinamento, que inclui adequar a intenção à ação (CARR; SHEPHERD, 2003, p. 37).

Os pacientes que sofreram TCE frequentemente apresentam padrōes anormais de movimento em membros superiores em decorrência de alteraçôes no tônus e distúrbios de sensibilidade que interferem, diretamente, no planejamento e execução do movimento voluntário. $\mathrm{O}$ objetivo nesta fase é "adequar" as respostas do paciente às suas capacidades atuais, trabalhando principalmente aspectos cognitivos e de desempenho funcional de membros superiores para na próxima fase trabalhar habilidades mais específicas, tanto cognitivas quanto motoras. (FISCHER; KANKISAKA, 2003, p. 561).

Depressão, maior labilidade emocional e reduçáo de afeto podem resultar de lesão neurológica em si. Os pacientes com lesão no hemisfério esquerdo tendem a mostrar maior depressão e labilidade emocional. (GUTMAN, 2005, p. 718).

De acordo com a avaliação inicial I estava com um padrão físico (aspecto motor), descrito por Davies (1996b) como problemas mais encontrados em pacientes que ainda não receberam orientaçôes sobre a execução de atividades em domicílio.

- ADM de movimentação de ombro incompleta;

- Encurtamento dos músculos flexores do cotovelo;

- Supinação incompleta do antebraço direito, mesmo de forma passiva;

- Limitação na ADM de abdução de ombro com braço em rotação externa e extensão do cotovelo;

- O joelho direito espástico em extensão e com dificuldade em liberar a espasticidade para funçôes tais como cruzar a perna para calçar o seu sapato, andar ou subir escadas;

- Os artelhos fletidos fortemente e aduzidos (garra);

- Pé em pronação com rotação medial de joelho;

- Equilíbrio comprometido (DAVIES, 1996b, p. 301).

Uma das mais difíceis sequelas do TCE é a mudança no autoconceito do indivíduo. $\mathrm{O}$ autoconceito é a imagem interna que a pessoa tem sobre a identidade humana pessoal, identidade sexual, imagem corporal, forças e limitaçôes pessoais e sua posição na família, no grupo de amigos e no 
meio social. Uma das características de quem sofreu TCE é que, embora a memória a curto prazo esteja com frequência alterada, a memória a longo prazo costuma permanecer intacta. $\mathrm{O}$ indivíduo tem uma memória clara de quem era antes da lesáo e deve agora resolver o conflito emocional de ter que abandonar o autoconceito de antes da lesão e reconstituir um autoconceito pós- lesão que seja ao mesmo tempo significativo e satisfatório (GUTMAN, 2005, p. 717).

$\mathrm{O}$ autoconceito derivado em grande parte dos papéis vitais que a pessoa desempenha. Após o TCE o indivíduo perde a condição de exercer a maioria dos seus papéis e a perda do papel profissional e a incapacidade de manter a si mesmo estáo intimamente ligados aos sentimentos de dependência e falta de controle pessoal (GUTMAN, 2005, p. 717).

Para fundamentar a prática terapêutica, foi escolhido o modelo ocupacional funcional (MOF). Este sugere que para a reabilitaçáo de déficits neurológicos, ou seja, para favorecer o aprendizado de habilidades que recuperassem a automanutenção da paciente com lesão cerebral são necessários:

- Determinar o que o aprendiz sabe;

- Estabelecer o objetivo da aprendizagem;

- Escolher técnicas de instrução coerentes com o que est sendo ensinado;

- Dar oportunidades para a prática, considerando o contexto e o programa;

- Oferecer feedback útil no momento certo;

- Testar o aprendiz em vários contextos apropriados para confirmar que ocorreu a aprendizagem;

- Discutir o progresso com relação aos objetivos e revisar a estratégia ou objetivos de aprendizagem como indicado (TROMBLY; RADOMSKI, 2005, p. 9).

A partir dos dados colhidos na entrevista e avaliação, os objetivos do tratamento foram traçados juntamente com a cliente e com a família. Os atendimentos foram realizados em seu domicílio e utilizados recursos pouco sofisticados, que estavam disponíveis no próprio ambiente.

Todas as atividades que proporcionem desenvolvimento, aprendizado, superação dos limites, bem como percepção e consciência das dificuldades, são objeto de análise e de intervenção terapêutica (TOLDRA, 2003, p. 54).

O modelo ocupacional funcional (MOF) tem como diretriz:
- 1) Para a adesão satisfatória no desempenho de papéis vitais, uma pessoa deve estar apta a realizar tarefas que, em sua opinião, componham o papel;

- 2) As tarefas estão compostas por atividades, que são as pequenas unidades do comportamento;

- 3) Para se estar apto a realizar uma dada atividade, deve-se possuir certas habilidades sensório-motoras, cognitivas, de percepção, emocionais e sociais;

- 4) As habilidades são desenvolvidas a partir das capacidades que a pessoa adquiriu através do aprendizado ou amadurecimento;

- 5) Essas capacidades desenvolvidas dependem de capacidades de primeiro nível que derivam dos atributos genéticos da pessoa ou substrato orgânico disponível (TROMBLY; RADOMSKI, 2005, p. 2).

Da teoria neuroevolutiva, foram utilizadas as técnicas de inibição e facilitação para normalização do tônus e para preparar a paciente para realizar a atividade com o melhor alinhamento biomecânico.

Bobath e Bobath notaram que, quando os pacientes aprendiam novos movimentos, muitas vezes utilizavam espontaneamente estes movimentos de maneira funcional sem tratamento adicional. Na ocupação como fim, o paciente participa diretamente da aprendizagem de uma tarefa ou atividade e dessa maneira o profissional utiliza atividades de forma terapêutica para influenciar as deficiências e dar oportunidades para aprendizagem e prticas motoras (TROMBLY; RADOMSKI, 2005, p. 526).

A partir daí aplicava a teoria do programa de reaprendizagem motora, favorecendo a aprendizagem do movimento, onde o indivíduo tem controle sobre suas açóes e fica capacitado a criar estratégias motoras para serem usadas de acordo com a mudança do ambiente. Os movimentos eram ensinados dando a sensação através da condução do membro durante a execução da atividade. É importante conhecer exatamente quais as reais necessidades do paciente para que os saberes possam ser usados no momento certo e de forma eficaz.

Os atendimentos iniciavam-se com alongamento ativo-assistido de membro superior. Foi escolhido um creme de uso diário de I para usar durante o alongamento, e a partir daí exploramos o seu potencial motor, sensorial - tátil, exterioceptivo - e cognitivo. Numa primeira tentativa, de colocar I de frente ao espelho, ela chorou muito ao ver sua imagem refletida e não conseguiu identificar as partes do 
rosto e do corpo. Outras experiências com o espelho foram vivenciadas por ela e no sétimo atendimento houve o reconhecimento da própria imagem. Passou a mão sobre a cicatriz do TCE e comentou que não se conformava. Ela chorou por alguns momentos, mas conseguiu controlar a emoção demonstrando progresso no aspecto emocional. Também foi capaz de reconhecer as partes do corpo e repetiu verbalmente o nome de cada uma, demonstrando evolução no aspecto cognitivo e motor. Quando finalizamos a atividade, foi dado o feedback, e ela, ao perceber o quanto havia evoluído com o tratamento, mostrou-se motivada; saiu pela casa dançando e pela primeira vez pediu à cuidadora para ir à padaria juntas.

Uma das premissas do MOF que as pessoas esforçam-se para alcançar sentimentos de satisfação, ou seja, sentimentos de eficiência pessoal e autoestima. Estes sentimentos derivam de estar responsável por sua própria vida, sendo competente no desempenho de papéis vitais (TROMBLY; RADOMSKI, 2005, p. 5).

Os indivíduos com TCE geralmente passam por estágios, que começam com a negação, na qual o indivíduo nega que esteja sofrendo de deficiências físicas, cognitivas e psicossociais. A negação pode impedir a terapia porque o paciente pode se negar a participar, acreditando que a terapia desnecessária. A negação gradualmente diminui medida que o paciente confronta-se continuamente com suas limitaçōes nas atividades básicas de vida diária. O segundo estágio o da raiva. Neste estágio o paciente fica cada vez mais consciente e torna-se frustrado e zangado porque a recuperação mais lenta do que o desejado.O próximo estágio a barganha. O paciente faz um trato com o criador de destinos, oferecendo-se para trabalhar o mais diligentemente possível na terapia se o criador trouxer de volta o estilo de vida anterior lesão. Muitas vezes este estágio traz motivação e otimismo crescentes. A depressão tende a surgir em seguida. $\mathrm{O}$ paciente começa a perceber a gravidade da lesão e seu significado para o resto de sua vida. A aceitação da lesão e das limitaçôes resultantes o próximo estágio do processo e necessário para que o indivíduo fique motivado o suficiente para tentar construir uma vida pós-lesão, que, embora drasticamente diferente das metas e expectativas de antes da lesão, não obstante traz propósito e valor pessoal. $\mathrm{O}$ tempo de transição entre estes estágios varia de acordo com a estrutura psíquica de cada sujeito (GUTMAN, 2005, p. 718).

Pensando na Terapia Ocupacional como profissão que estuda a práxis, ou seja, o homem em atividade, e que para isso é necessário o desenvolvimento de competências, todo o trabalho executado teve como objetivo o aprimoramento de competências, para desta forma proporcionar ao sujeito o sentimento de autossuficiência e autoestima. O MOF distribuiu os papéis vitais em três domínios relacionados a aspectos de autodefiniçãa: automanutenção, progresso pessoal e realização pessoal (TROMBLY; RADOMSKI, 2005, p. 5).

Fez parte dos atendimentos a habilitação dos familiares e cuidadores, para lidar com as limitaçôes reais de I.

Como outros membros da família ou da equipe são frequentemente aqueles que irão reforçar as habilidades recém-aprendidas, o treinamento da família é fundamental para reforçar o aprendizado das habilidades recém-aprendidas, e garantir que o paciente faça a transferência das habilidades obtidas em sessóes anteriores de treinamento. (DIANE, 2005, p. 150).

De acordo com as demandas principais do caso estudado foi tido como eixo condutor do tratamento o desenvolvimento de competências para que o sujeito recuperasse a sua automanutenção.

Os papéis da automanutenção estâo associados com o desenvolvimento e manutenção de si próprio, inclusive a família e o lar. (TROMBLY; RADOMSKI, 2005, p. 5).

Assim como foi definido por Toldra (2003, p. 55):

O desenvolvimento do potencial criativo e de transformação é parte intrínseca do conteúdo terapêutico. Isso envolve a capacidade do profissional de despertar a motivação e o desejo de experimentar novas experiências, novas habilidades, o sabor de realizar atividades, de sentir-se realizado, proporcionando à pessoa influenciar no próprio processo.

Durante o período inicial dos atendimentos, foram observadas evoluçóes no estado geral de I. Ela demonstrava interesse pelas sessóes, confiança na execução motora da marcha, estabilidade de humor e melhora nos aspectos cognitivos. Era possível vê-la andando sozinha por dentro de casa sem apoiar nos móveis, cumprimentando as pessoas com a mão direita (afetada) e usando a mesma para segurar objetos. Certo dia, foi solicitado que encontrasse o creme para a execução do alongamento, ela orientou-se no espaço e o localizou com pouca dificuldade. Abriu-o usando as duas mãos e passou no pé direito (afetado) sem que fosse dado comando verbal. Após o clareamento da ação executada, I compreendeu a complexidade da tarefa que já era capaz de realizar independentemente e, entusiasmada, esboçou algumas palavras, mas, ao identificar a dificuldade para pronunciar o que 
gostaria de dizer, sentiu-se frustrada, disse que náo gostaria mais de fazer a atividade, mas conseguiu controlar as emoçôes, e chorou por um curto período. Em situaçóes como a relatada, frente à frustração de I, era dito a ela que momentos difíceis ela já havia vivido muitos e que saiu como heroína da maioria deles. Para isso, perdeu algumas batalhas, deu passos em falso e nem assim deixou de acreditar e lutar por seus ideais. Assim ela encarou o fracasso, na execução das atividades, como um elemento que faz parte dessa nova batalha que está vivendo, e que mesmo com dificuldades não deixará de lutar pelo seu ideal, que desta vez é restabelecer a sua saúde práxica. Ao longo dos quinze primeiros atendimentos foi capaz de reconhecer partes de seu corpo sem precisar vê-lo no espelho. Passava creme nas áreas em que eram denominadas, demonstrando evolução no aspecto sensorial, na consciência e reelaboração da imagem corporal. A maioria das atividades era realizada de forma bimanual. Passou a ter mais confiança em seu potencial funcional e de acordo com isso a iniciativa para resolver problemas começou a aparecer. Houve um aumento na autoestima e no senso de competência, consequentemente o humor se estabilizou e sua participação nas tarefas da casa começou a acontecer.

A reabilitação traz um pouco de cura, de descoberta, de readaptação, de reabilitação e pressupóe o bem-estar da pessoa e sua capacidade de enfrentar as dificuldades. (TOLDRA, 2003, p. 55).

Onze meses após o início do acompanhamento da Terapia Oocupacional, I era capaz de realizar sua automanutenção em relação às ABVDs (considero aqui $\mathrm{ABVDs}$ como atividades básicas de vida diária, esse termo envolve mobilidade funcional e cuidados pessoais). Recentemente, durante um dos atendimentos, uma das irmâs de I fez o seguinte comentário: "Você acredita que I entrou para o quarto, fechou a porta e trocou de roupa sozinha? Agora ela está assim... não pede mais ajuda para isso. E o dia que ela entrou no banheiro, fechou a porta e tirou a roupa para tomar banho... eu quase morri do coração. Não esperava que ela fosse ficar táo independente". Diante da conscientização de I e de seus familiares de que muitas de suas habilidades estavam recuperadas, a participação da mesma nos eventos que envolvem sua rotina passou a ser maior. I começou a ajudar nas tarefas de casa, das quais realizava antes de sofrer o TCE. Além disso, tem saído em companhia das irmãs ou da cuidadora para ir à padaria ou a algum lugar próximo de casa. A família comenta com bastante euforia sobre a mudança no comportamento de I.
É possível perceber que I tem apresentado grandes evoluções no seu estado de saúde geral. Estas vêm associadas ao empenho dos profissionais envolvidos em seu tratamento e, claro, na dedicaçáo da família, da cuidadora e da própria paciente. A recuperação de habilidades favoreceu a independência e autonomia de I nos papéis de automanutenção e a reinserção no convívio familiar.

\section{Discussão}

A partir da premissa sob o referencial de saúde, como saúde práxica, o terapeuta ocupacional passa a encarar seu objeto de estudo, com os olhos não só sob suas deficiências, mas principalmente percebendo suas habilidades preservadas, valorizando e ressaltando tudo o que é saudável. As deficiências motoras, cognitivas, sensoriais, são obstáculos significativos para o desempenho ocupacional e de papéis vitais. O relato de caso ajuda a ilustrar como é possível que a perda de uma habilidade não seja condição para o sujeito manter-se em disfunção ocupacional, pois outras capacidades podem se adaptar para permitir a realização da atividade.

Aumentar a participação e a percepçáo do indivíduo, seus sentimentos e comportamentos relacionados com o seu funcionamento diário, incluindo, mas náo se limitando, ao diagnóstico, é uma intervenção que engloba, bem estar físico, mental, psicológico, emocional. Contribuindo para a atuação em relacionamentos sociais, com a família e amigos, com sensação de pertencimento a um grupo, que nao seja o da doença, mas da sociedade como um todo.

Usar uma abordagem teórica ampla enriquece o olhar do profissional frente ao sujeito assistido. Acredito que o terapeuta ocupacional deve se permitir conhecer os vários tipos de recursos de tratamento que existem, principalmente por ser um profissional que lida com a individualidade humana. Dessa forma o que pode ser eficaz para um sujeito pode náo ser para outro; e o profissional deve estar preparado para lançar mão de fundamentaçóes diversas. Quaisquer que sejam os instrumentos de atuação que optemos por utilizar, precisamos focar, principalmente, sobre as prioridades, recursos e restriçóes dos indivíduos, sem perder de vista o viés principal, que são os fundamentos da profissão.

Através do referencial teórico, foi possível orientar a minha prática e favorecer a automanutençáo da paciente em estudo. Plausível perceber que, através da aquisição de habilidades, aumentaram-se o senso de competência e a autoestima da paciente, e isso favoreceu o seu envolvimento no processo terapêutico e a ressignificação de seus papéis vitais, principalmente o de manutençấo de si própria. 
A diferença e até as divergências entre as abordagens de reabilitaçáo de pacientes com déficits neurológicos contribuíram para um raciocínio crítico e fundamentado no objeto de estudo da Terapia Ocupacional. Pude perceber que é possível ampliar os recursos/abordagens de tratamento desde que a fundamentaçáo teórica da Terapia Ocupacional esteja interiorizada pelo terapeuta, e este seja capaz de discernir o momento de se apropriar de cada um.

\section{Considerações finais}

A intervenção terapêutica ocupacional favoreceu a aquisição e/ou aprimoramento de habilidades e proporcionou à paciente o sentimento de eficiência para engajar-se, de forma satisfatória, nos próprios papéis vitais. Essa conclusão reafirma as premissas do modelo ocupacional funcional, que diz que o senso de competência e a autoestima interferem no grau de satisfação do sujeito. Apesar de suas limitações, I vem recuperando sua saúde práxica, conseguindo atuar em determinadas situaçóes, novamente, como um indivíduo práxico, ou seja, associando o tipo e a qualidade da ação realizada, recuperando o seu estado evolutivo, criativo, expressivo, produtivo, lúdico e transformador.

O processo de reabilitação foi conduzido sob a perspectiva da deficiência como parte de um estado de saúde. Ao contrário da prática reducionista, em que o tratamento se resume à função perdida e desvaloriza os aspectos que, de fato, constituem o ser humano, este caso esteve sob a óptica holística. Foi possível contemplar os valores da paciente, favorecendo sua reabilitação, ampliando sua interação com pessoas, papéis e com o ambiente em que estava inserida. Um elemento que contribuiu para isso foi a participação ativa da mesma e dos familiares, além dos demais profissionais envolvidos. Dessa forma o trabalho foi enriquecido pela totalidade de saberes e o resultado foi uma melhora na condição de vida do sujeito em questão.

\section{Referências}

ALVES-MAZZOTTI, A. J. Paradigmas Qualitativos. In: ALVES-MAZZOTTI, A. J. O Método nas Ciências Naturais e Sociais: Pesquisa Quantitativa e Qualitativa. São Paulo: Pioneira,1998. cap. 6, p. 130-146.

AMARO, S. Visita Domiciliar: Guia para uma Abordagem Complexa. Porto Alegre: AGE, 2003.
ASSOCIAÇÃO BRASILEIRA DO TERAPEUTA OCUPACIONAL - ABRATO. Disponível em: <http:// www.abrato.com.br/mostra_caderno.aspx?id=243>. Acesso em: 02 mar. 2012.

CARR, J. H.; SHEPHERD, R. B. Programa de Reaprendizagem Motora para o Hemiplégico Adulto. São Paulo: Manole, 1988.

CARR, J. H.; SHEPHERD, R. B. Hipóteses que Fundamentam a Intervençáo da Fisioterapia: Perspectivas Teóricas e Históricas. In: CARR, J. H.; SHEPHERD, R. B. Ciência do Movimento. 2. ed. São Paulo: Manole, 2003. cap. 1-2, p. 1-37.

DAVIES, P. M. O Programa para a Casa. In: DAVIES, P. M. Passos a seguir, um manual completo para o tratamento da hemiplegia no adulto. São Paulo: Manole, 1996b. cap. 15, p. 299-305.

DAVIES, P. M. Os Problemas que Ninguém V. In: DAVIES, P. M. Passos a Seguir: um manual para o tratamento da hemiplegia no adulto. Sáo Paulo: Manole,1996a. cap. 1, p. 01-08.

DAVIES, P. M. Problemas Associados com a Perda da Atividade do Tronco na Hemiplegia. In: DAVIES, P. M. Exatamente no Centro. São Paulo: Manole,1996c. cap. 3, p. 37-53.

DIANE, F. Atividades de Vida Diária. In: PEDRETTI, L. W.; EARLY, M. B. Terapia Ocupacional: capacidades práticas para as disfunçôes físicas. 5. ed. São Paulo: Roca, 2005. cap. 13, p. 132-183.

FISCHER, A. L.; KAKISAKA, S. M. Traumatismo Cranioencefálico. In: SAURON, F. N. et al. Terapia Ocupacional na Reabilitação Física. São Paulo: Roca, 2003. cap. 28, p. 551-564.

GUTMAN, S. A. Trauma Cranioencefálico. In: PEDRETTI, L. W.; EARLY, M. B. Terapia Ocupacional: capacidades práticas para as disfunçôes físicas. 5. ed. São Paulo: Roca, 2005. cap. 38, p. 704-738.

MACHADO, M. C. A Saúde Práxica e o Ser Práxico. In: MACHADO, M. C. Rumo ao Objeto da Terapia Ocupacional. Belo Horizonte: Ediçôes Cuatiara, 1991. cap. 2, p. 23-58.

SHUMWAY-COOK, A. Fisiologia do Controle Motor. In: SHUMWAY-COOK, A. Controle Motor Teoria e Aplicaçôes Praticas. 2. ed. São Paulo: Manole, 2003. cap. 3. p. 47-84.

TOLDRA, R. C. Reflexóes Acerca da Terapia Ocupacional na Atenção Pessoa Portadora de Deficiência Fisica. In: PÁDUA, E. M. M.; MAGALHĀES, L. V. Terapia Ocupacional Teoria e Prática. 3. ed. Campinas: Papirus, 2003. cap. 3, p. 54-55.

TROMBLY, C. A.; RADOMSKI, M. V. Terapia Ocupacional Disfunçōes Físicas. 5. ed. São Paulo: Santos Ltda. 2005.

\section{Contribuição dos Autores}

Vanessa Maciel Oliveira contribuiu elaborando o texto manuscrito, realizando busca da literatura científica utilizada, levantamento e descrição dos dados, análise dos resultados, organização das fontes, revisão final; Miriam Cândida Silvia e Dias contribui realizando indicação de literatura específica, revisão do texto, análise dos resultados e orientação sobre organização das fontes. 